\title{
PREPARATION AND PROPERTIES OF SOLAR COMPOSITE MATERIALS FOR MARINE ENVIRONMENT
}

\author{
$\mathrm{XU}, \mathrm{J} . *-\mathrm{BU}, \mathrm{J}$ \\ Zhejiang Industry Polytechnic College, Shaoxing 312000, China \\ *Corresponding author \\ e-mail:xujiandeuw1231@163.com \\ (Received $1^{\text {st }}$ Jun 2019; accepted $2^{\text {nd }}$ Sep 2019)
}

\begin{abstract}
In order to strengthen the advantages of resin matrix composites such as light weight, high strength, fatigue resistance, corrosion resistance and electrical insulation, glass fiber shows great application potential in the field of Marine engineering. Composite profiles were prepared by pullextrusion process, and the retention rate of mechanical properties was higher after $1000 \mathrm{~h}$ test in the neutral salt spray test chamber. The extruded composite profile was used as the frame of the solar module for the Marine environmental test. After a long time of marine environmental testing, the appearance of the component had no obvious defects. The strength retention rate of the composite profile was high, and the maximum power attenuation of the component was less than 5\%. The results show that the composite profile can be used as a solar panel frame in marine environment.
\end{abstract}

Keywords: vinyl ester resin, resin matrix composites, glass fiber, ocean, solar energy

\section{Introduction}

With the development of science and technology, single material properties cannot meet the needs of production and social development. It has become a trend to combine things with different properties and exert the excellent comprehensive properties of materials by compound effect, and to make such materials become the mainstream of the material industry (Zhang et al., 2017). Composites have emerged at the right moment, and the most widely used composites are glass fiber reinforced resin matrix composites, namely glass fiber reinforced plastics (Huang et al., 2018). Glass fiber reinforced resin matrix composite has the advantages of light weight, high strength, fatigue resistance, corrosion resistance and electrical insulation, etc. Pultrusion preparation process is an important method for the preparation of high performance, high fiber content, fast and low-cost composite profiles (Chen et al., 2017). Marine environmental factors must be considered when pultrusion profiles are used in Marine engineering.

Composite material is a new type of structural material, because of its light weight, high strength, corrosion resistance and other characteristics, and has excellent performance in the long-term use in marine environment. Therefore, composite materials have greater application in ocean engineering, in the mid-1940s, the United States used composites in shipbuilding for the first time, composite materials in our country were first used of military purposes, and then gradually extended to the civilian life, although after rapid development, but the marine environment application still needs more development. Nowadays, the application of composite materials in the marine environment is mainly used in the construction of ships and the production of supporting products, including fishing boats, yachts and lifeboats. At the same time, glass fiber reinforced composite material is used as seawater pipeline, fire and waterproof pipeline in offshore oil and gas development.

The marine environment is complex, mainly including Marine hydrological environment, overhead meteorological conditions, geological environment and other 
environmental factors, which have many influencing factors on the material. In order to apply composite materials more efficiently in the marine environment, research on the performance change of composite materials in the marine environment is a hot topic at present. The main factors of corrosion of materials in marine environment include salt content, temperature, sunshine and $\mathrm{pH}$ value. The study of the weather resistance of composite materials mainly refers to the assessment and evaluation of the weather resistance of composite materials by placing them in the outdoor natural environment and making them subject to the comprehensive effect of various factors.

Solar composite material is a new kind of material which is made by using advanced material preparation technology to optimize the composition of materials with different properties. Due to its many advantages, the application of solar composite materials in the Marine environment is increasingly valued. The Marine environment is extremely complex, and multi-traditional metal materials such as air humidity, high salinity and corrosive substances adhesion are a great challenge. Therefore, solar composite materials are of great significance in the application field of Marine engineering. Solar composites in the field of ocean engineering application is of great significance. However, due to the limitations of science and technology and materials, more research efforts are needed. Nachtane et al. (2018) explored and analyzed the properties of glass fiber reinforced composites applied to steel structures. Sutherland et al. (2018) summarized the application of composite riser pipe, coil-able composite pipe, composite mooring cable, underwater weapon shell, propeller and other components, and looked forward to the main technical development direction of composite materials for offshore drilling platforms in the future. Javier et al. (2017) summarized the research progress on accelerated aging of yacht fiber reinforced composites in Marine environment, and analyzed the influence of solar ultraviolet light, thermal oxygen, salt spray, seawater and other factors on their corrosion aging mechanism, material properties and variation rules.

In this paper, based on the research and experiment on the profile of solar composite material, a new material was developed for better marine operation and to provide technical support for the construction of marine engineering.

\section{Experimental materials and methods}

\section{Experimental materials and equipment}

The grades, models and manufacturers of raw materials required in the experiment are shown in Table 1, and the experimental equipment is shown in Table 2.

\section{Sample preparation}

A certain amount of vinyl vinegar resin liquid $(0.5 \mathrm{~g})$ should be weighed into a mixing vessel, then according to the proportion of the corresponding mass (according to 1:100 mass ratio) of the additive should be added to the resin, which should be stirred to mix well with a glass rod.Then it should be let stand for deaeration, then mixing liquid should be added into the mould, after curing under $100{ }^{\circ} \mathrm{C}$ and a half hours, the samples are bagged for use. Fiberglass reinforced vinyl cool resin composite was prepared by pull-extrusion process. The resin, initiator and flame retardant were mixed according to the weight ratio of 100:1.3 1.5:15. The mixture was evenly stirred and injected into the soaking tank. Considering that the composite material surface needs to be protected in practical application, after processing the sample, the surface part of the sample was 
sprayed with fluoropolymer vinegar semi-gloss enamel, which can prevent the corrosion of mold, salt fog and moisture, and there are different colors to choose from.

Table 1. Experimental materials and manufacturers

\begin{tabular}{c|c|c}
\hline The raw material & Class/model & The manufacturer \\
\hline Vinyl ester resin & Atlac430 & Jinling DSM Resin Co. Ltd \\
The glass fiber & 4800Tex & Shandong Taishan Glass Fiber Co. Ltd \\
Tert-butyl benzoate peroxide (TBPB) & Industrial-grade & Nobel Peroxide (Tianjin) Co. Ltd \\
Bis (4-tert-butyl cyclohexyl) carbon peroxide & Industrial-grade & Taiyuan Chemical Co., Ltd. Fine branch factory \\
Antimony trioxide & Senior pure & Shanghai Aifeng Antimony Trade Co., Ltd \\
Decabromodiphenyl ether & Senior pure & Shanghai Aifeng Antimony Trade Co., Ltd \\
Fluorine polyurethane semi-gloss enamel & TS96-61 & Tianjin Lighthouse Coating Co. Ltd \\
Anhydrous ethanol & Analysis of pure & Harbin Yongchang Chemical Company \\
Sulfuric acid & Analysis of pure & Harbin Yongchang Chemical Company \\
Hydrochloric acid & Analysis of pure & A chemical distribution station in Harbin \\
Sodium hydroxide & Analysis of pure & A chemical distribution station in Harbin \\
Sodium chloride & Analysis of pure & Harbin Yongchang Chemical Company \\
Acetone & Analysis of pure & A chemical distribution station in Harbin \\
Acid ester (P16) & Industrial-grade & Taiyuan Chemical Co., Ltd. Fine branch factory \\
\hline
\end{tabular}

Table 2. Experimental equipment

\begin{tabular}{c|c|c}
\hline Device name & Model & Origin \\
\hline Composite pultrusion production line & LJ-1020 & Harbin Institute of FRP \\
Electric blast drying oven & $101-2 \mathrm{~A}$ & Tianjin Taist Industrial Co. Ltd \\
Infrared spectrometer & Spectrum 100 & Perkin Elmer Co., Ltd \\
Differential scanning calorimeter & Pyris6 & Perkin Elmer Co., Ltd \\
Thermogravimetric analyzer & TGA Q50* & TA Instruments \\
ZEISS optical microscope & $200 \mathrm{MAT}$ & Carl Zeiss GmbH \\
Universal material testing machine & CMT5504 & Meister Industrial Systems Co. Ltd \\
Electronic balance & FA2004A & Shanghai Jingtian Electronic Instrument Co., Ltd \\
Bar-hardness tester & HBa-1 & Wuxi Institute Of Metrology \\
Salt spray corrosion test chamber & LY W-015 & Shanghai Blue Leopard Test Equipment Co., Ltd \\
Lamp aging test chamber & - & Homemade \\
Thermostatic water bath & DK-600 & Shanghai Jinghong Test Equipment Co., Ltd \\
\hline
\end{tabular}

Vinyl composite profiles pultrusion speed is $0.1 \mathrm{~m} / \mathrm{min}$ commonly, it is $0.2 \mathrm{~m} / \mathrm{min}$, pultrusion speed when the production efficiency is higher, but too fast pultrusion speed is easy to make the product out of the mold has not fully solidified,in order to guarantee the quality of the products, this study used the pultrusion speed of $0.1 \mathrm{~m} / \mathrm{min}$, the traction of $50 \mathrm{kn}$, and three temperature ranges: $100 \sim 110{ }^{\circ} \mathrm{C}, 120 \sim 130{ }^{\circ} \mathrm{C}, 130 \sim 140$ ${ }^{\circ} \mathrm{C}$. In the actual production process, only by adjusting the temperature of the three zones according to the technological conditions a composite with excellent extruded profile properties can be prepared. The pultrusion profile was prepared and then the material was cut into the required size according to the size of the solar module. 


\section{Mechanical performance test}

Tensile performance test was performed according to GB/T 3354-1999 "test method for tensile properties of oriented fiber reinforced plastics". GFRP (Glass Fiber Reinforced Polymer) profile tensile performance test sample size was $230 \mathrm{~mm} \times 15 \mathrm{~mm}$ $\times 2 \mathrm{~mm}$, the test was carried out on universal testing machine (Zhao et al., 2018). As the material is easy to be destroyed in the clamping position during the tensile process, aluminum alloy reinforcing sheets should be pasted at both ends of the tensile sample, with the thickness of the reinforcing sheets being $1.5 \mathrm{~mm}$. The adhesive agent used to bond the reinforcing sheets is a mixture of 618 resin and polyphthalein, so as to ensure that the reinforcing sheets do not fall off during the test (Jiao et al., 2018). Tensile properties were tested at room temperature with a loading speed of $2 \mathrm{~mm} / \mathrm{min}$ (Fig. 1).

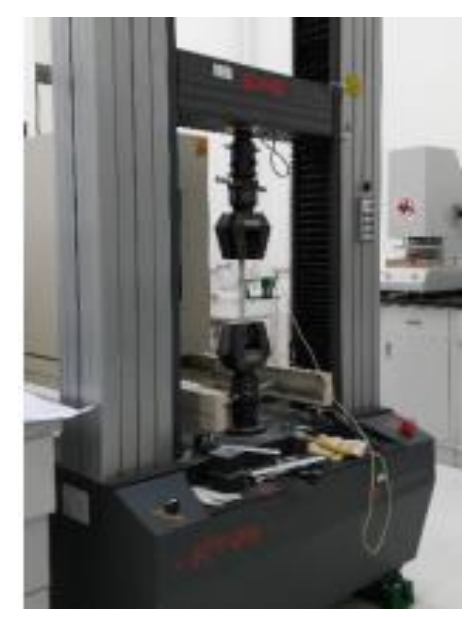

Figure 1. Tensile test

The bending performance test was carried out on the same universal test machine. The bending sample size was $100 \mathrm{~mm} \times 15 \mathrm{~mm} \times 4 \mathrm{~mm}$, and the three-point bending mode is adopted for testing. The loading head radius was $\mathrm{R}=5 \mathrm{~mm} 0.2 \mathrm{mrn}$, the bearing fillet radius was $R=2 \mathrm{~mm} 0.2 \mathrm{mrn}$, and the loading speed was $2 \mathrm{~mm} / \mathrm{min}$. The experimental results show that its tensile and bending properties are good and not easily damaged (Fig. 2).

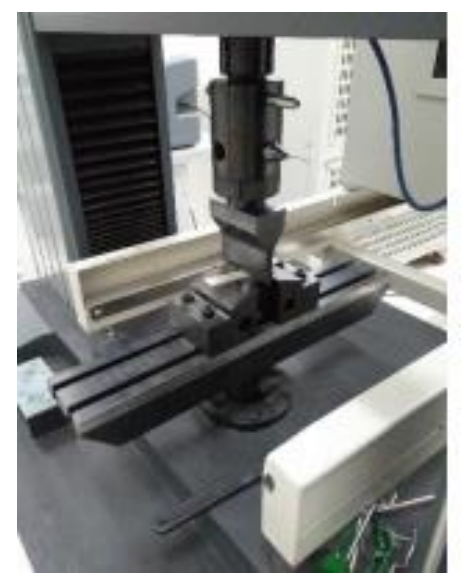

Figure 2. Bending test 


\section{Corrosion resistance test}

According to the provisions of GB/T 10125-2012 "salt fog test for corrosion test of artificial atmosphere", the test of GFRP profile's resistance to neutral salt fog corrosion was conducted in the neutral salt fog test box. See Figure 3 for the test box. In the neutral salt spray test, the FRP composites were divided into two groups. One group was sprayed with fluorine polyurethane semi-gloss enamel, while the other group was not treated. The two groups were processed according to the tensile sample size and the bending sample size, and tested in the neutral salt spray test chamber (Vimalathithan et al., 2018). Neutral salt spray test for $1000 \mathrm{~h}$ was divided into 7 sections in time regarding sampling observations, sampling time were 24 h, 48 h, 72 h, 168 h, 336 h, $672 \mathrm{~h}$, and $1000 \mathrm{~h}$ from the test start time, take 3 samples for performance test at each age, including appearance evaluation, the weight test, the tensile strength test, the bending strength test and calculate its strength retention (Lopresto et al., 2018).

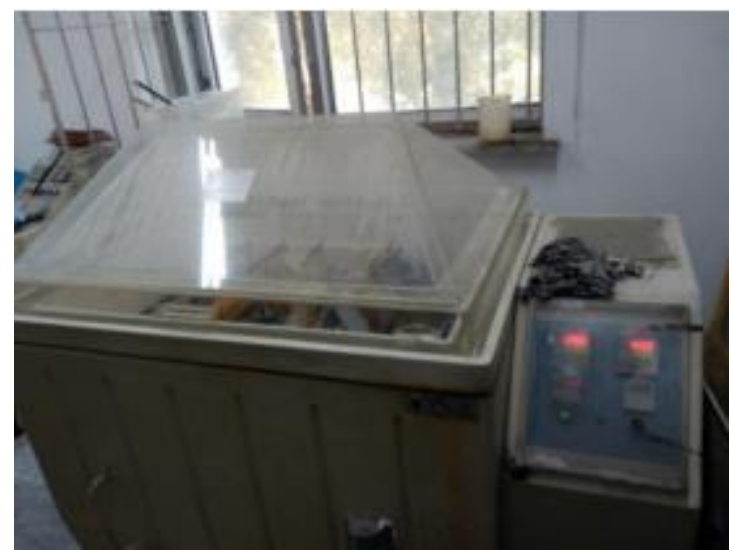

Figure 3. Neutral salt spray test box

After the test, to reduce the sample on the adhesive and to reduce corrosion,dry the sample in the room for $0.5 \mathrm{~h} \sim 1 \mathrm{~h}$ before cleaning, and then surface should be gently cleaned with flowing water with a temperature below $40{ }^{\circ} \mathrm{C}$, to remove salt on the surface of the sample, then with an air pressure from the sample of about $300 \mathrm{~mm}$ less than $200 \mathrm{kpa}$ samples should be blow dried immediately (Alia et al., 2018). The experimental results show that this kind of material has strong corrosion resistance and meets the selection conditions of marine engineering equipment materials.

\section{Marine environmental test of composite profiles}

The composite extruded profile was installed on the YGE 145 series solar photovoltaic panels as the frame and applied in the marine environment. The test was conducted at the sanya marine environment test station in China (Barkanov et al., 2017; Tucci et al., 2018). The size of the solar panel is $1470 \mathrm{~mm} \times 680 \mathrm{~mm} \times 25 \mathrm{~mm}$, and the composite frame is prepared according to the size of the solar panel (Barkanov et al., 2018). The test was carried out in three areas: (1) splash platform test area, which can simulate the waves on the deck; (2) offshore platform test area, which can simulate the navigation environment of ships; (3) the atmospheric insolation test area, which is an offshore and coastal area, simulates the ship docking environment. 10 composite frame components and 10 aluminum alloy frame components were installed in each test area. 
During the test, the test environment conditions and the working status of solar photovoltaic modules were monitored in real time. Marine environment test period of 9 months, sampling at different time points, test after test the working characteristic of solar photovoltaic components and mechanical properties of the composite frame, through three areas of the test after the marine environment, the photovoltaic components and the borders of corrosion resistance, prevent ageing, impact resistance, wind resistance, waterproof performance can be evaluated (Barkanov et al., 2018).

\section{Experimental results and analysis}

\section{Analysis of mechanical properties}

In this paper, the mechanical properties of composite profiles prepared by pultrusion process were tested in accordance with relevant standards. The basic properties of composite profiles are listed in Table 3.

Table 3. Mechanical properties of composite profiles

\begin{tabular}{c|c|c|c|c}
\hline $\begin{array}{c}\text { The } \\
\text { serial } \\
\text { number }\end{array}$ & A pilot project & Test results & Execution standard & Sample size mm \\
\hline 1 & The tensile strength $\mathrm{MPa}$ & 786 & GB/T3354-2014 & $230 \times 15 \times 2.3$ \\
2 & The tensile modulus $\mathrm{GPa}$ & 53.6 & & \\
3 & The compression strength $\mathrm{MPa}$ & 312 & GB/T 1448-2005 & $12 \times 10 \times 4$ \\
4 & The compression modulus GPa & 11.6 & & \\
5 & The bending strength MPa & $1.01 \times 10^{3}$ & GB/T3356-2014 & $100 \times 15 \times 2.3$ \\
6 & Bending modulus GPa & 40.2 & GB/T 1451-2005 & $120 \times 10 \times 4$ \\
7 & Impact toughness KJ/m2 & 442 & GB/T 1463-2005 & $50 \times 10 \times 2.3$ \\
8 & The density of $\mathrm{kg} / \mathrm{m} 3$ & $2.03 \times 10^{3}$ &
\end{tabular}

\section{Corrosion resistance analysis}

Figure 4 is the change curve of weight gain rate of composite profile after salt spray test. It can be seen from the figure that the quality of the two samples increased gradually from the beginning to $336 \mathrm{~h}$. From $336 \mathrm{~h}$ to $1000 \mathrm{~h}$, the weight gain rate of the samples gradually decreased, which was slower than the earlier trend. Because with the extension of the salt spray corrosion time, the absorption of water molecules in the samples was gradually saturated, and the weight gain rate of the two samples was between $0.12 \%$ and $0.14 \%$. The reasons for weight gain of composite materials during salt spray test are as follows. First, water molecules in salt spray environment penetrate into the sample through the surface or resin and fiber sections; Another reason is that salt mist is attached to the sample (Baran, 2017).

The maximum stress that the material bears before tensile fracture is the tensile strength of the material, salt fog corrosion test before and after the change of the tensile strength of the sample values to represent composite material corrosion resistance calculation of salt spray test after tensile strength retention rate, neutral salt spray test after surface spraying fluorine polyamine vinegar semifinished enamel the tensile properties of the composite material test results are shown in Table 4. 


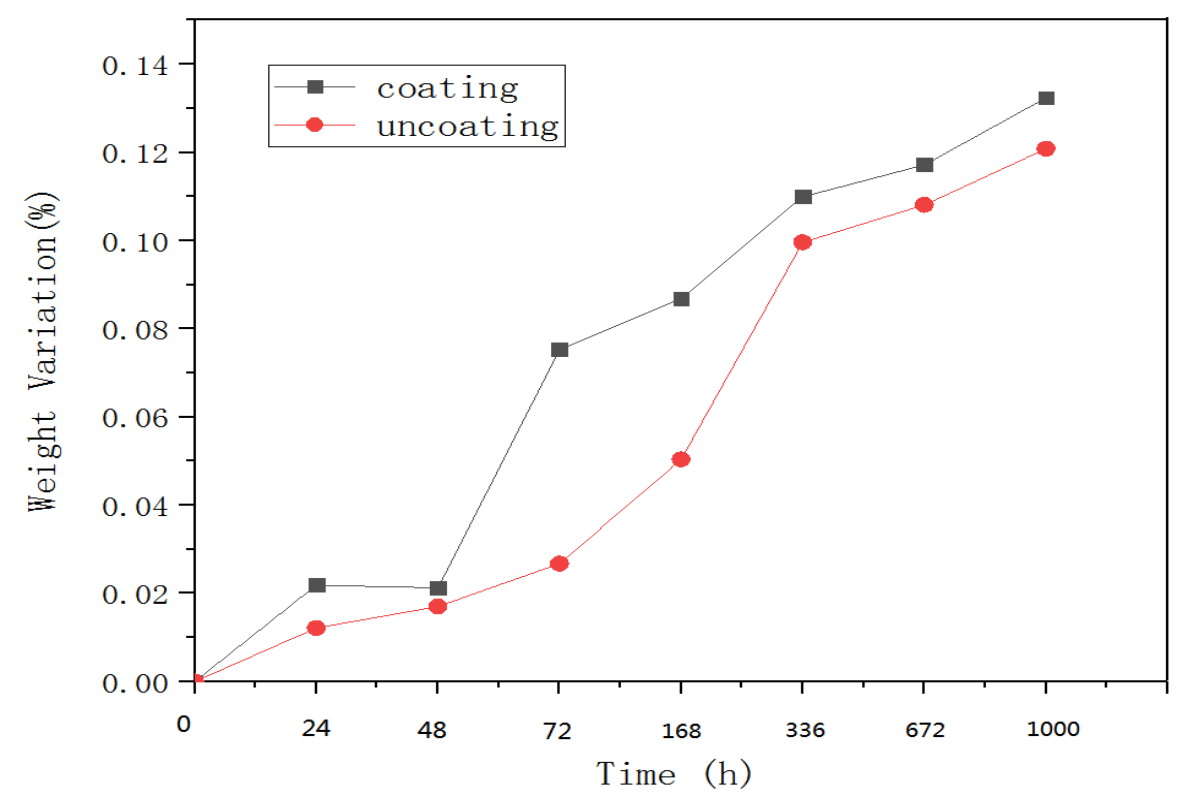

Figure 4. Quality change of composite profile after salt spray test

Table 4. Tensile properties of fluorinated polyurethane semi-gloss enamel composite profiles after salt spray test

\begin{tabular}{c|c|c|c}
\hline $\begin{array}{c}\text { Salt spray test time } \\
(\mathbf{h})\end{array}$ & $\begin{array}{c}\text { The tensile strength } \\
(\mathbf{M P a})\end{array}$ & $\begin{array}{c}\text { Modulus of elasticity } \\
(\mathbf{G P a})\end{array}$ & $\begin{array}{c}\text { Strength retention } \\
(\boldsymbol{\%})\end{array}$ \\
\hline 0 & 788.14 & 53.37 & 100 \\
168 & 659.73 & 49.19 & 83.71 \\
336 & 678.75 & 47.08 & 86.12 \\
672 & 711.805 & 45.31 & 90.31 \\
1000 & 678.76 & 49.18 & 86.12 \\
\hline
\end{tabular}

Table 5 shows the $1000 \mathrm{~h}$ salt spray test for surface treatment of the tensile properties of the composite material. The bending performance shows high bending strength retention at each point in time, basically no bending strength loss, after $1000 \mathrm{~h}$ neutral salt fog corrosion specimens, the tensile strength of the composite material and bending strength retention rate was higher, which indicated that the composite material in a neutral salt fog corrosion environment can be used for a long time and able to maintain good tensile and bending properties (Safonov et al., 2017).

Table 5. Bending properties of untreated composite profiles after salt spray test

\begin{tabular}{c|c|c|c}
\hline $\begin{array}{c}\text { Salt spray test time } \\
(\mathbf{h})\end{array}$ & $\begin{array}{c}\text { The tensile strength } \\
(\mathbf{M P a})\end{array}$ & $\begin{array}{c}\text { Modulus of elasticity } \\
(\mathbf{G P a})\end{array}$ & $\begin{array}{c}\text { Strength retention } \\
(\boldsymbol{\%})\end{array}$ \\
\hline 0 & 1378.68 & 45.03 & 100 \\
168 & 1321.12 & 40.70 & 95.82 \\
336 & 1309.05 & 41.77 & 94.94 \\
672 & 1316.18 & 45.69 & 95.46 \\
1000 & 1327.20 & 41.79 & 96.26 \\
\hline
\end{tabular}




\section{Analysis of the influence of marine environment on mechanical properties and photovoltaic characteristics}

Will the solar energy components used in ocean environment, respectively in atmospheric exposure test, offshore platform test area and splash experimental zone (Fig. 5) experiment platform, and set the aluminum alloy frame component as the control group, the Marine environment test for 9 months, study the mechanical properties of composite frame and through the comparison and analysis of composite frame with aluminium alloy frame's influence on the photovoltaic cell characteristics.

Table 6 shows the results of marine environment test of composite bending performance of solar module frame, after a period of time of test in three experimental areas in Sanya, the bending strength of the composite was increased, the strength retention rate increased, within the scope of the marine environment test time, as the sea trial was the longer the higher bending strength test values were observed (Chadel et al., 2017). This is because in the process of sea trials, composite material solar energy components border were mainly affected by sunlight and salt fog environment, ultraviolet ray is contained in sunlight, Ultraviolet irradiation can cause post-curing of composite material frame and also cause aging damage to the material. According to the test results, during the Marine environment test, the post-curing rate of composite material is higher than the rate of destruction by ultraviolet light, which is manifested as the increase of bending strength.

Table 6. Component frame bending performance after marine environmental test

\begin{tabular}{c|c|c|c}
\hline Test area & Trial period of age & $\begin{array}{c}\text { The bending strength } \\
(\mathbf{M P a})\end{array}$ & $\begin{array}{c}\text { Strength retention } \\
\mathbf{( \% )}\end{array}$ \\
\hline \multirow{3}{*}{ Splash platform test area } & The initial value & 1013 & 100 \\
& Three months & 1076 & 106 \\
& Five months & 1200.6 & 118 \\
\hline \multirow{3}{*}{ Offshore platform test area } & The initial value & 1013 & 100 \\
& Six months & 1092.4 & 108 \\
& Nine months & 1396.25 & 137 \\
\hline \multirow{3}{*}{ Atmospheric exposure test area } & The initial value & 1013 & 100 \\
& Six months & 1074.2 & 106 \\
& Nine months & 1329.8 & 131 \\
\hline
\end{tabular}
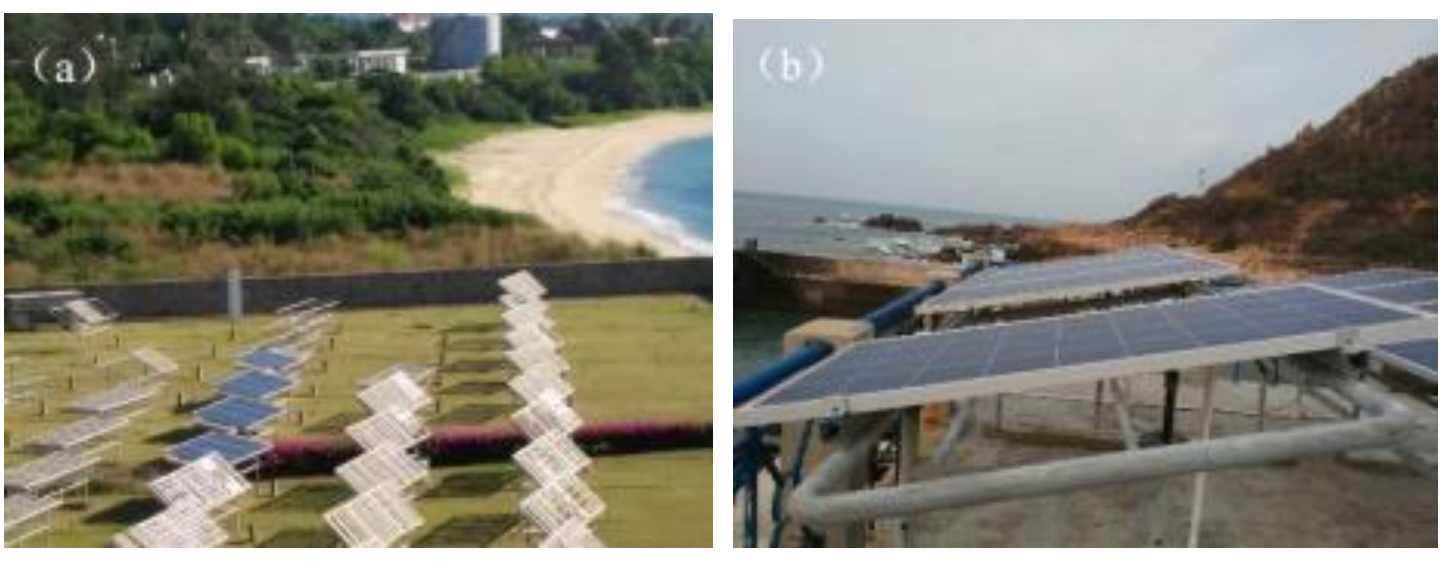


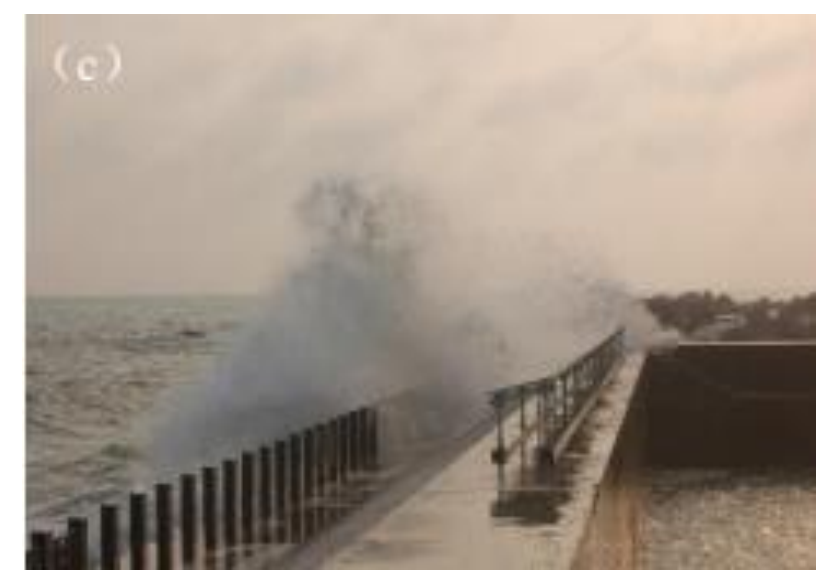

Figure 5. Marine environment test platform. (a) Atmospheric exposure test area; (b) offshore platform pilot zones; (c) splash platform test area

Table 7 shows the tensile properties of composite solar panel frame after the Marine environmental test. According to the experimental results, it can be found that the tensile strength of composite frame varies in different regions.

Table 7. Tensile properties of component frame after marine environmental test

\begin{tabular}{c|c|c|c}
\hline Test area & Trial period of age & $\begin{array}{c}\text { The tensile strength } \\
(\mathbf{M P a})\end{array}$ & $\begin{array}{c}\text { Strength retention } \\
(\boldsymbol{\%})\end{array}$ \\
\hline \multirow{3}{*}{ Splash platform test area } & The initial value & 690 & 100 \\
& Three months & 673 & 97.5 \\
& Five months & 661 & 95.8 \\
\hline \multirow{3}{*}{ Offshore platform test area } & The initial value & 690 & 100 \\
& Six months & 668 & 96.8 \\
& Nine months & 756 & 109.6 \\
\hline \multirow{3}{*}{ Atmospheric exposure test area } & The initial value & 690 & 100 \\
& Six months & 716 & 103.8 \\
& Nine months & 716 & 103.8 \\
\hline
\end{tabular}

Figure 6 for the test during the day some inverter record the change of the components of the power curve, the component rises as the sun began to work, power increased, reached the highest at noon as time extended again after power down, repeat this process every day, and a set of components (20) in the case of the weather is sunny every day capacity up to $18.5 \mathrm{~kW} / \mathrm{h}$.

Table 8 shows the component power parameters of solar photovoltaic modules nine months after the marine environment test. In accordance with the relevant standard requirement after Marine environmental testing performance of solar module test, the attenuation of maximum power does not exceed $5 \%$ of the experimental measurements before and after the test component of power attenuation is still less than 5\%, the component can work normally and no obvious flaw appearance, shows that composite material can be used as a solar module frame used in the marine environment. 


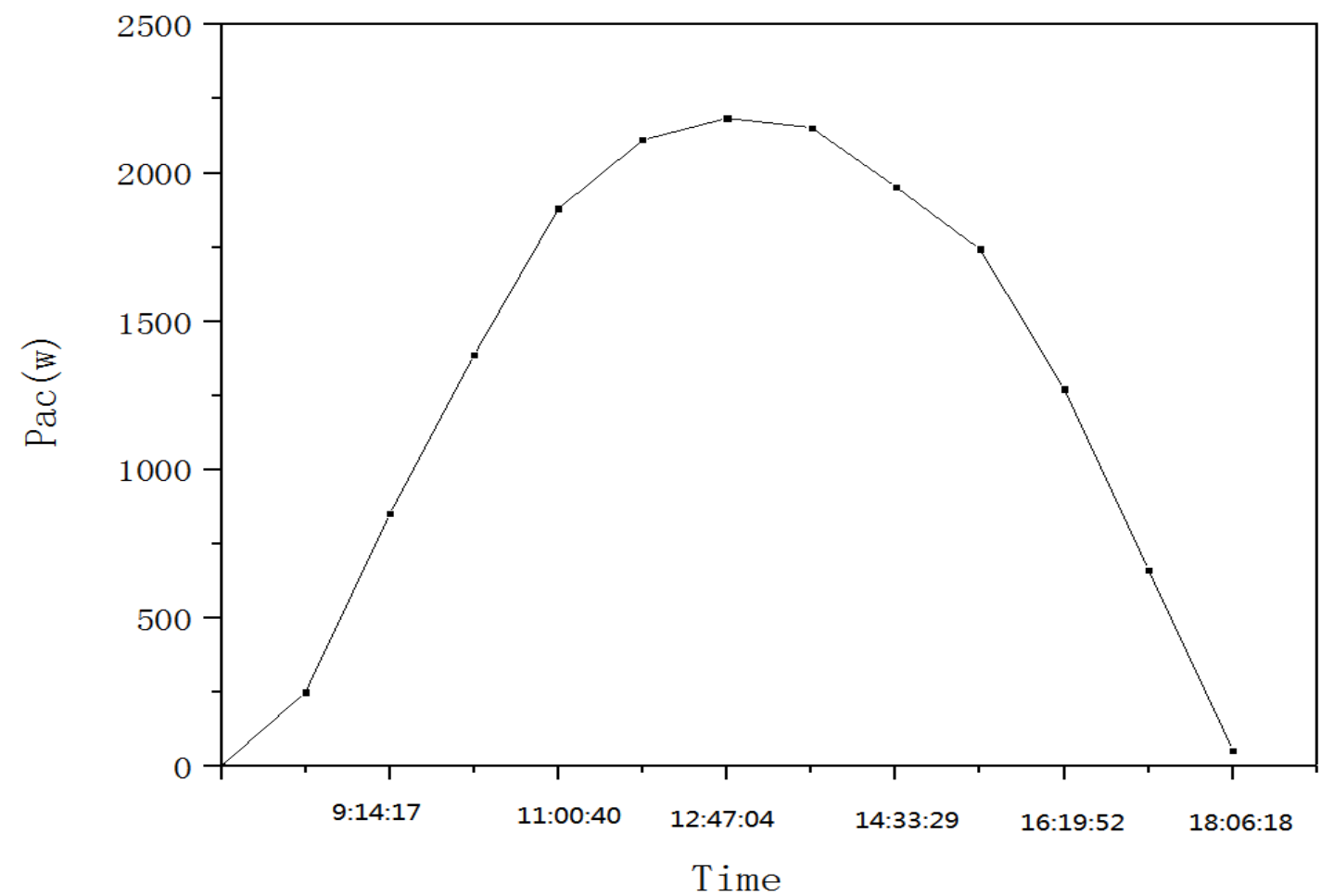

Figure 6. Power curve of marine environmental test in one day

Table 8. Component power parameters nine months after the marine environmental test

\begin{tabular}{c|c|c|c|c}
\hline Test area & Component classification & $\begin{array}{c}\text { Maximum power } \\
\text { before test }(\mathbf{w})\end{array}$ & $\begin{array}{c}\text { Maximum power } \\
\text { after test (w) }\end{array}$ & $\begin{array}{c}\text { The power } \\
\text { attenuation }(\boldsymbol{\%})\end{array}$ \\
\hline Offshore platform & Composite frame & 148.529 & 142.892 & 4.02 \\
Test area & Aluminium alloy frame & 147.551 & 141.352 & 4.34 \\
Atmospheric exposure & Composite frame & 147.840 & 141.615 & 4.25 \\
Test area & Aluminium alloy frame & 148.276 & 141.966 & 4.08 \\
\hline
\end{tabular}

\section{Discussion}

From tensile results, after salt spray test, the tensile strength of the composites decreased, but with the extension of time, the salt fog corrosion did not cause faster strength degradation rate, but in a certain range fluctuations occurred. The reason is that early test of composite profiles in the salt fog environment water absorption, moisture absorption quantity are the important factors influencing the mechanical properties of composite materials, composite materials absorb moisture makes fiber easy to fall off from the substrate, causing internal clearance, and clearance have accelerated the absorption of moisture causing the loss of the performance of composite materials (Safonov et al., 2017). With the extension of time, the moisture absorption quantity saturated. The mechanical properties of the composite material decreased slowly. After $1000 \mathrm{~h}$ of neutral salt spray corrosion, the tensile strength retention rate of the composite profile is $86.12 \%$, with a high tensile strength retention rate (Afanasyev et al., 2018). 
The tensile strength of the composite solar panel frame in the splash platform test area decreased slightly after a period of ocean test, but the degree of reduction was not obvious. The tensile strength of the composite solar panel frame in the offshore platform test area decreased at the initial stage, but increased with the extension of the test time. The tensile strength of the frame of the composite solar module in the atmospheric exposure test area increased with the extension of the test time. Similarly, the ultraviolet radiation from the sun may lead to post-curing of the composite frame during the test. When the curing degree is greater than the corrosion degree, the tensile strength of the material increases, which is roughly the same as the change trend of bending strength.

When solar photovoltaic module is used in marine environment, it is easy to accumulate more salinity on the surface of the module because of the large amount of salt fog in the marine environment. When the accumulated particulate matter is mixed with rainwater, sea water or other liquid substances, and then irradiated by sunlight for a long time, it will form a strong spot which is not easy to fall off. If this spot just blocked a series branch of the module, the blocked part could not perform photovoltaic effect and became a load consuming current, forming a "hot spot". When the temperature of this part rises to a certain extent, it may cause damage to the whole battery assembly. The existence of hot spot will cause the attenuation of the maximum power of the module, and the smaller the size of the hot spot is, the more severe the hot spot effect will be, the more the number of hot spot, the more attenuation of the module will occur. After the marine environment test, the maximum power of the solar module has been attenuated. After nine months test, the maximum power attenuation of the solar module is less than $5 \%$. The module can work normally, which shows that the module with composite frame can be used in the marine environment.

\section{Conclusion}

In the research of marine composite materials, it is necessary to pay attention to the coordinated development with marine ecosystem and avoid environmental pollution. On this basis, professional research structures should be established for the research of various materials to provide strong financial and technical support for the innovation of materials. The test results of the mechanical properties of the composite profiles show that the composite insulation has the advantages of light weight and high strength. The corrosion resistance of the composite material was evaluated through the neutral salt spray corrosion test. It can be seen that with the extension of the test time, the quality of the sample increased due to the hygroscopicity of the sample, and its tensile strength and bending strength retention rate were higher, indicating that the composite material had better performance in the salt spray environment. After the marine environment test, the bending and tensile properties of the composite frame were tested. The test results showed that the bending strength of the composite profile increased with the extension of the test time, and the retention rate of its tensile strength was higher, indicating that the composite was suitable for the marine environment. After the Marine environment test, the electrical performance of the solar module was tested. The test results showed that the maximum power of the solar module decreased after the Marine environment test,nine months after the test, the maximum power attenuation is less than $5 \%$, the component can work normally, equipped with composite frame component it can be used in the marine environment. 


\section{REFERENCES}

[1] Afanasyev, D. A., Mirzoev, K. Y., Ibrayev, N. K. (2018): Influence of defects of nanostructured zno films on the photovoltaic characteristics of perovskite solar cells. IOP Conference Series: Materials Science and Engineering, Volume 289, Conference 1.

[2] Alia, C., Jofre-Reche, J. A., Suárez, J. C., Arenas, J. M., Martín-Martínez, J. M. (2018): Characterization of the chemical structure of vinyl ester resin in a climate chamber under different conditions of degradation. - Polymer Degradation \& Stability 153: 88-99.

[3] Baran, I. (2017): Analysis of pultrusion process for thick glass/polyester composites: transverse shear stress formations. - Advanced Manufacturing: Polymer \& Composites Science. https://doi.org/10.1080/20550340.2016.1269037.

[4] Barkanov, E., Akishin, P., Miazza, N. L., Galvez, S. (2017): Ansys-based algorithms for a simulation of pultrusion processes. - Mechanics of Composite Materials \& Structures 24(5): 377-384.

[5] Barkanov, E., Akishin, P., Miazza, N. L., Galvez, S., Pantelelis, N. (2018): Experimental validation of thermo-chemical algorithm for a simulation of pultrusion processes. Journal of Physics: Conference Series, Volume 991, Conference 1.

[6] Chadel, M., Bouzaki, M. M., Chadel, A., Petit, P., Sawicki, J. P., Aillerie, M., et al. (2017): Influence of the spectral distribution of light on the characteristics of photovoltaic panel. Comparison between simulation and experimental. - AIP Conference Proceedings 1814. https://doi.org/10.1063/1.4976273.

[7] Chen, Y., Yapei, Z. U., Gong, J., Sun, C., Wang, C. (2017): Effect of al film on the electromagnetic properties of glass fiber reinforced resin matrix composite. - Acta Metallurgica Sinica. DOI: 10.11900/0412.1961.2017.00178

[8] He, Y., Xiao, L., Li, L. (2017): Research on the influence of pv cell to thermal characteristics of photovoltaic/thermal solar system. - International Journal of Energy Research 41. DOI: 10.1002/er.3711.

[9] Huang, Q., Qin, W., Garoushi, S., He, J., Lin, Z., Liu, F., et al. (2018): Physicochemical properties of discontinuous s2-glass fiber reinforced resin composite. - Dental Materials Journal 37(1): 95-103.

[10] Javier, C., Leblanc, J., Shukla, A. (2017): Shock Response of Composite Materials Subjected to Aggressive Marine Environments. - In: Sutton, M., Reu, P. L. (eds.) International Digital Imaging Correlation Society. Proceedings of the First Annual Conference, 2016. Springer International, pp 169-171.

[11] Jiao, W., Cai, Y., Liu, W., Fan, Y., Long, J., Jiao, W., et al. (2018): Preparation of carbon fiber unsaturated sizing agent for enhancing interfacial strength of carbon fiber/vinyl ester resin composite. - Applied Surface Science 439: S0169433217338746.

[12] Lopresto, V., Papa, I., Langella, A. (2018): Basalt fibres in vinyl ester resin laminates under low velocity impact conditions. - Journal of Dynamic Behavior of Materials 4(3): 328-335.

[13] Nachtane, M., Tarfaoui, M., Saifaoui, D., Moumen, A. E., Hassoon, O. H., Benyahia, H. (2018): Evaluation of durability of composite materials applied to renewable marine energy: case of ducted tidal turbine. - Energy Reports 4: 31-40.

[14] Safonov, A. A., Carlone, P., Akhatov, I. (2017): Mathematical simulation of pultrusion processes: a review. - Composite Structures 184: S0263822317324212.

[15] Sutherland, L. S. (2018): A review of impact testing on marine composite materials, part iii: damage tolerance and durability. - Composite Structures 185: 512-518.

[16] Tucci, F., Rubino, F., Carlone, P. (2018): Strain and temperature measurement in pultrusion processes by fiber Bragg grating sensors. - AIP Conference Proceedings 1960, https://doi.org/10.1063/1.5034837.

[17] Vimalathithan, P. K., Barile, C., Vijayakumar, C. T. (2018): Investigation of kinetic triplets for thermal degradation of thermally cured vinyl ester resin systems and lifetime predictions. - Journal of Thermal Analysis \& Calorimetry 133(3): 1-11. 
[18] Zhang, D., Sun, Y., Wang, Y. (2017): Failure behavior and damage mechanism of multiaxial glass fiber reinforced resin matrix composites. - Acta Materiae Compositae Sinica. DOI: 10.13801/j.cnki.fhclxb.20160606.004.

[19] Zhao, D., Tian, F., Yalin, Y. U., Zhang, B., Meng, B., Feng, Q., et al. (2018): Preparation and performance of lithium ionic liquid/epoxy vinyl ester resin solid electrolyte. - Acta Materiae Compositae Sinica 35(2): 253-259. 